\title{
Epidemiology, Zoonotic Aspect and Current Epidemiological Situation of Q Fever in Poland
}

\author{
Krzysztof Niemczuk and Monika Szymańska-Czerwińska \\ National Veterinary Research Institute, \\ Department of Cattle and Sheep Diseases, Pulawy, \\ Poland
}

\section{Introduction}

$\mathrm{Q}$ fever (for query fever) is a zoonosis caused by Coxiella burnetii, a small gram-negative $(0.2$ to $0.4 \mu \mathrm{m}$ wide, 0.4 to $1 \mu \mathrm{m}$ long), obligate-intracellular bacterium. Historically, it was considered as Rickettsia but gene-sequence analysis classifies Coxiella genus in the order Legionellale, family Coxiellaceae (Seheradi, 2003).

Pleomorphic bacteria are classified in three groups: large cell variants (LCV), small-cell variants (SVC) and small dense cells (SDC). The SCVs and the SDCs are the most frequent forms in the host and certainly (the most) resistant forms in the environment. The LCV form of Coxiella burnetii, which shares features common with gram-negative bacteria, diffuse chromatin and process clearly distinguishable outside and cytoplasmic membranes with LPS exposed on the surface. The LCVs are larger, more pleomorphic and metabolically active than the SCVs and the SDCs. The SDCs have been visualised in LCV as endospores, and they may be liberated upon the lysis of LCV or binary transverse fission with unequal cell division. The SDCs alone have never been isolated, free-living amoeba can provide an intra-cellular niche for SDC formation and survival of Coxiella burnetii in the environment. Binary transverse fission was observed both in the SCVs and the LCVs in cells cultured. The form changes within lifecycle of Coxiella burnetii are strategy to survive (Arricau-Bouvery \& Rodolakis, 2005).

Coxiella burnetii occurs in two phases. In the culture, it transforms from a virulent phase I type to an avirulent phase II. In the phase II, bacteria have alerted expression of cell wall lipopolysaccharide (LPS), do not occur in nature and are killed by macrophages (Hotta et al., 2002). The survival strategy of the bacteria is based on multiplication in mature phagosomes of monocytes/macrophages. The virulence is connected to the LPS expression. The virulent Coxiella burnetii entered into monocytes through $\alpha_{v} \beta_{3}$ integrin and survived inside the cells (Dellacasagrande et al., 2000). Avirulent variants were more easily ingested than virulent bacteria but they were eliminated by monocytes. Their phagocytosis was mediated by $\alpha_{v} \beta_{3}$ integrin-IAP complex and CR3, suggesting that the efficiency of Coxiella burnetii phagocytosis mainly results from the activation and CR3-dependent phagocytosis, thus 
preventing CR3 engagement. It is possible that Coxiella burnetii induced impairment of CR3 function results from uncoupling $a v \beta_{3}$ integrin from IAP (Capo et al., 1999).

The heterogeneity among strains of Coxiella burnetii is low degree (Vodkin et al., 1986). However, when DNA from 38 Coxiella burnetii isolates was examined by using restriction fragment length polymorphism (RFLP) analysis, six genomic groups (I to VI) were detected (Hendrix et al., 1991). The genome size of Coxiella burnetii nine Mile strain amounts to 2.1 $\mathrm{Mb}$. The size of genome is highly variable among different isolates and ranging from 1.5 to $2.4 \mathrm{Mb}$ (Willems et al., 1998). Genomic groups (I, II and III) are associated with animal, tick or acute $\mathrm{Q}$ fever in human, whereas group IV and V are isolated from human $\mathrm{Q}$ fever endocarditis cases. Group VI isolates were obtained from feral rodents in dungway, and their pathogenicity is unknown (Maurin \& Raoult, 1999).

Coxiella burnetii is the well-known causative agent of $\mathrm{Q}$ fever, but neglected as zoonosis. $\mathrm{Q}$ fever has spread worldwide both in humans and in animals (Kruszewska et al., 1996). Coxiella burnetii can infect many animal species including mammals, birds and arthropods such as ticks. Generally, $\mathrm{Q}$ fever is asymptomatic, but it can lead to abortions and stillbirths in mammals. In these animals, Coxiella burnetii can induce pneumonia as well as abortion, stillbirth and delivery of weak lambs, calves or kids, which are the most frequent clinical sings of the disease. Coxiella burnetii in humans causes highly variable clinical manifestations ranging from acute to fatal chronic infections. However, about $60 \%$ of the infections are asymptomatic seroconversions. Acute $Q$ fever is mainly a flu-like disease, or atypical pneumonia or hepatitis. $Q$ fever is essentially an airborne disease. The infections occur after inhalation of aerosols generated from infected placentas, body fluids or contaminated manure. Transmission of this pathogen is generally associated with abortion of domestic ruminants, particularly sheep (Arricau-Bouvery \& Rodolaski, 2005).

Tetracyclines are the best for treating $Q$ fever. Although, $Q$ fever endocarditis has been treated by the use of the combination of doxycyline with chloroquinolone. The time of treatment is very long and it takes for 18 to 36 months in order to cure chronic $Q$ fever (Maurin \& Raoult, 1999).

\section{Entry and survival Coxiella burnetii in the cells}

Coxiella burnetii after the entry into the organism, is phagocytosed by macrophages. The entry of Coxiella burnetii into monocytes and macrophages is lakely to be critical for its adaptation to host cells and development of $Q$ fever (Capo et al., 1999). The bacterial cells multiply in phagolyosome and next cells burst, spreading the pathogens throughout the body. In animals, they are mostly located in the lung, mammary gland, testis, lymph nodes, uterus and placenta. The disease process may be also extended to the liver and cardiovascular system. There are views that the animal can be infected lifelong but it takes place in a latent form. The amplification of larger number of bacteria and prevalence of typical symptoms of $\mathrm{Q}$ fever occurs during pregnancy or by the action of immunosuppressive agents. Coxiella burntii survives and divides in a phagolisosome (Fig.1). The small and large forms express different genes that permit the bacterium to survive in the acidified environment of phagolisosome (Arricau-Bouvery \& Rodolaski, 2005). 


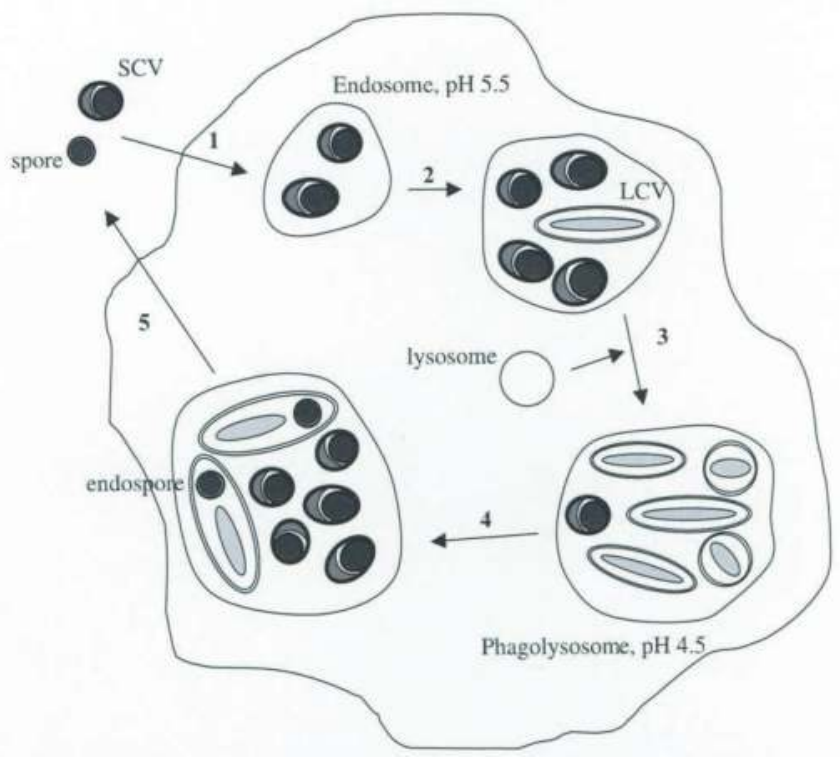

Fig. 1. Life cycle of the bacteria (Arricau-Bouvery \& Rodolakis, 2005) (1). Entry of the spore in the eukaryotic cell and acidification of the endosome of the phagosome. (2) Multiplication of small-cell variants (SCV) by transverse binary fission and differentiation to large-cell variants (LCV). (3) Fusion of the endosome with the lysosome, acidification of the phagolysosomal. (4) Multiplication of LCV by transverse binary fission, differentiation of LCV to SCV and development of the polar endospore in LCV. (5) Release of the spore and SCV out of the cell.

\section{Epidemiology}

\subsection{Zoonotic aspects}

In humans, $Q$ fever occurs the most often in direct contact with infected animals in slaughterhouses, as well as fur and veterinarians. Infections from human to human are very rare, and may have place especially in hospitals where patients infect the others through sputum released during coughing. Sporadic human infections of $Q$ fever occurred after contact with infected parturient women, via transplacental transmission resulting in congenital infections, during autopsies, intradermal inoculation or blood transfusion. It has been postulated that transmission of Coxiella burnetii among mammals occurs mainly via inhalation of infected dust and aerosols (Maurin \& Raoult, 1999). It is very difficult to explain some cases of Coxiella burnetii infections. The literature dates showed that there is possibility of sexual transmission of $Q$ fever among mammals. The studies showed that heifers infected intravaginally with a suspension of Coxiella burnetii shed bacteria in their urine few days later. Moreover studies on nine Polish patients, who were employed in Spain during sheep shearing season showed occurrence of antibodies to Coxiella burnetii antigens in their serum. The antibodies were detected also in their spouses but they did not occur in sera from the other family members. Moreover, scanning electron microscopy of 
spermatozoa cells from patients with $Q$ fever has revealed the presence of attached bacteria. (Kruszewska et al., 1993, 1996).

The incidence of $Q$ fever in human occur very often during spring and early summer when it is warm, dry and windy because the environmental survival allows it to be transported by wind far away from its original source. Such environmental conditions in Jenna (German) in June 2005 caused that Coxiella burnetii - infected sheep, grazing and lambing on the meadow bordering a residential brought about infection in 331 human (Gildsdorf et al., 2007).

The source of human infections is often unknown, although sheep and goats are more frequently related to $Q$ fever outbreaks in humans (Glisdorf et al., 2005). The largest $Q$ fever outbreaks occurred in the Netherlands, involving 3,921 human cases in the years 2005-2009. The dairy goats and sheep were considered the source of the human $Q$ fever outbreak. The disease was found in about 60 farms these animals (Roest et al., 2011).

The infection by ingestion (mainly drinking raw milk) is probably a minor factor of risk, and at present it constitutes even a point of controversy (Maurin \& Raoult, 1999; Krumbiegel \& Wiśniewski, 1996). Drinking contaminated milk has induced seroconversion in human volunteers but without clinical signs (Benson, 1963). However, some studies have reported clinical diseases linked to the ingestion of cheese (Hatchette et al, 2001; Fishbein \& Raoult, 1992) but infection by inhaling contaminated dust or aerosols cannot be excluded. The serological and molecular studies performed in the herds, where antibodies were present in blood of lactating cows, showed that Coxiella burnetii DNA was detected in the milk $(8.7 \%)$. The antibodies were detected only in the serum of $1 \%$ of young cattle selected from these herds (Muskens, 2011).

Coxiella burnetii in humans causes highly variable clinical manifestations ranging from acute to fatal chronic infections. Initially, there is typically a noticeable slight increase in internal body temperature lasting for several days. In addition, eye inflammation is stated, as manifested by greater amounts of fluid seromucinous flowing from the conjunctiva sac and nose. These general symptoms do not give rise to suspicion of $Q$ fever. Sometimes only the prevalence of many cases of people with the acute symptoms of flu can indicate the occurrence of the disease in animals. It comes more often to premature births and miscarriages. Swelling and local haemorrhages can be observed in the placenta of infected animals. The further course of disease depends on the degree of virulence of the agent and the immune status of animals. Acute form of $Q$ fever is mainly a flu-like disease, atypical pneumonia or hepatitis. Atypical pneumonia is characterised by fever, headache and myalgia. Despite the prevalence of pneumonia, cough can be absent. The hepatitis could be asymptomatic, only with the raise of transaminase levels, or the infectious hepatitis - rarely with jaundice (Fournier et. al., 1998).

In about $5 \%$ of the cases, the disease may become chronic form and it can lead to the endocarditis, chronic fatigue syndrome or repeated abortions. Endocarditic is the most frequent. It represents $1.5-2.5 \%$ all human cases of endocarditis. Chronic fatigue syndrome is characterised by an inappropriate fatigue, myalgia, arthralagia, night sweats and changes in mood. This chronic forms occur very often in Australia (Arricau-Bouvery \& Rodolaski, 2005). In pregnant women, Coxiella burnetii can cause placentitis leading to abortion, neonatal death, premature birth and low birth weight. The risk of chronic $Q$ fever leading to repeating miscarriages, is very high when the infection occurs during pregnancy (Arricau- 
Bouvery \& Rodolaski, 2005). Despite the isolation of Coxiella burnetii in the placenta and milk sick of mothers, children are born healthy (Lepe et al., 1999). Mortality in humans is relatively low at 1-2\%, except for tropical countries where it amounts to up to $9 \%$ (Moquin et al., 2002).

\subsection{Reservoirs}

Cattle, goats and sheep are considered the primary reservoirs that human contamination comes from. Epidemiological data indicated that dairy cows are more frequently chronically infected than sheep, and they are the most important source of human infections. The duration time of Coxiella burnetii excretion in infected animals depends on species and type of samples tested (Arricau-Bouvery N. \& Rodolakis, 2005) (Tab. 1).

Ticks have been considered a reservoir and a vector of Coxiella burnetii. In the nature, there are about 40 species of ticks transmitting the infections including Rihicephalus sanguineus, Amblyomma triuguattum (Maurin \& Raoult, 1999). The infection is transmitted from one stage to the next in the ticket cycle, and transovarian infection is observed. Ticks become infected after ingestion of infected mammal blood that in the time of the bacteremia. Microorganisms multiply mainly in the epithelial cells of the middle tick gut, then penetrate the intestinal wall, hemocytes and connective tissue of internal organs. Hence an infected tick is a carrier of the Coxiella burnetii for life, and its saliva may contain very high concentration of agent $\left(10^{8}-10^{11}\right)$ (Niemczuk, 2010). Coxiella burnetii in ticks, as in mammals, are in phase I and they are highly infectious. Morover, ticks are not considered essential in the natural cycle of Coxiella burnetii infections in livestock because animals can have many other opportunities to become infected. Ticks may play a significant role in the transmission of coxiellosi among the wild birds and vertebrates such as rodents and lagomorphs (Maurin \& Raoult, 1999).

Cats and dogs may be reservoirs of C. burnetii. Dogs may be infected by tick bite, consumption of placentas or milk from infected ruminants, and the aerosol route. In the literature, the cases of $Q$ fever human infections after contact with parturient cats are described in Nova Scotia (Kosatsky, 1984). Moreover, wild mammals, including horses, rabbits, swine, camels, water buffalo, rats and mice constitute the reservoirs of Coxiella burnetii. The serological studies of rats in the UK have shown anti-phase II antibody seroprevalences ranging from 7 to $53 \%$ among wild brown rat populations (Webster et al., 1995).

Birds, including pigeons, chickens, ducks, geese and turkeys can be infected with coxiellosis. Infected domestic poultry can be the sources of infections in human. People become infected by consumptions of raw eggs or inhalation of infected fomites (Maurin \& Raoult, 1999).

According to world experts on counter-terrorism, the agent that causes $Q$ fever, is considered as an effective component of biological weapon (Arricau \& Rodolaski, 2005). It is a potential agent of bioterrorism because of its accessibility, low infection dose, resistance to environmental degradation, and aerosol route of transmission. The minimum number of pathogens is required for human infection is 1-10 microorganisms. According to WHO, 50 kilograms of powder containing Coxiella burnetii can cause the comparable number of cases to tularemia or anthrax (Spicer, 1994; Moquin 2002). Q fever, although not characterised by high mortality, is important in wartime because the disease is severe, and the patient requires long-term care. Furthermore, the high resistance of the bacteria to drying, moisture, high or low temperature, promotes long-term being in the air, on skin, wool and straw 
(Prusakowski, 2001), for example experiencing up to 2 years in human faeces, to 6 years in the ticks' feces, 2-3 years in the water, 1 year in the fur, 1 month in meat, and 1-2 months in dairy products (Little, 1999; Maurin \& Raoult, 1999). Physical factors and especially pasteurisation kills germs in 15 seconds, while ultraviolet radiation is not an effective way to get rid of this microbe.

\section{Prevention}

Prevention of Coxiella burnetii shedding in cattle is critical to control the spread of the pathogen between animals and from animals to humans. A herd or a flock should be considered clinically infected with $Q$ fever when abortion or stillbirths have occurred, positive PCR results confirming the presence of Coxiella burnetii on specimens from affected animals, positive results in the serology test. In cattle herds, the occurrence of a series of abortion: for herds less than 100 animals 2 abortion or more in the month or 3 abortions in the year; for herds more than 100 animals more than $4 \%$ of cows with abortions in the year, is the major warning sing to be taken into account (Sidi-Boumedine et al., 2010).

Proceedings in the environment of healthy animals include a serological test of animals fur, quarantine of imported animals, the prohibition on animal breeding farms from areas where infection occurred, the serological tests of crossing animals, the fight against ticks and rodents. If $Q$ fever occurs, the following activities should be performed: the district veterinarian must notify diagnostic laboratory indicating a positive result, sporadic cases should be eliminated, the animals should be selected to serologically positive and negative in the case of numerous infections in the herd, the dynamics of antibodies should be studied in animals showing the presence of antibodies, disinfection of rooms should be performed, farrowing should be separated, placenta and the stillborn foetuses should be protected after each delivery, the direction of $\mathrm{Q}$ fever should be examined in newborn animals.

The newest study made in Denmark reported an increased risk of becoming infected with Coxiella burnetii for herds where farmers had bought cattle from other herds. Therefore, as a general rule, the purchase of animals should be avoided as much is possible, even if tests before introduction are implemented (EFSA Panel on Animal Health and Welfare (AHAW), 2010).

Prevention of Coxiella burnetii shedding in cattle or sheep and goat is critical to control the spread the pathogen. $Q$ fever vaccination of animals is not widely used because it is protective and safe only for animals that are uninfected at the time of vaccination. Moreover, extensive evaluation of the protective effect of such a vaccination on animal and human health compared to the cost of such prophylactic measures is lacking. There are two types of vaccines. The first one contains formalin-killed whole-cell vaccine preparations (WCV) and the second one - chloroform methanol-extracted bacterial residue (CMR). A WCV from the Henzerling strain ( $Q$ vax, CSL Limited, Parkville, Victoria, Australian) has been commercially available and used from human vaccination in Australia since 1989 (ArricauBouvery \& Rodolaski, 2005). Among 942 no immune abattoir workers in Australia who were vaccinated, no $Q$ fever case was diagnosed during 18 month whereas 34 cases were recorded among 1,349 unvaccinated controls (Marmion et al., 1984). This vaccination is very useful in the protection of exposed populations such as veterinarians or breeders of animals. A 
soluble vaccine containing trichloroacetic acid-extracted antigen from phase I Coxiella burnetii nine mile strain was successfully used in Czechoslovakia. In animal, the vaccines composed of inactivated whole phase I bacteria are the most effective. Bacterial shedding in milk and placentas was strongly reduced in infected animals vaccinated with phase I vaccines. Available vaccines are prepared with a single strain and therefore, they are monovalent. The recent works have shown that the vaccines reduce the shedding of Coxiella burnetii. These results are very important because of limiting the clinical disease in animals and human (Arricau-Bouvery \& Rodolaski, 2005).

\section{Laboratory diagnosis}

The diagnosis of $\mathrm{Q}$ fever remains difficult and epidemiological studies. Regarding the diagnosis of $\mathrm{Q}$ fever, several tools are available for direct and indirect detection of Coxiella burnetii. The studies are often based on the serological investigations. Although, the serological methods are useful. They do not allow for the identification of Coxiella burnetii shedding animals. Some infected animals can be seropositive without sheding Coxiella burnetii, and the others can shed the bacteria and remain seronegative, what is of great concern and could have an important impact both on animal and public health. Moreover, the serological test can distinguish vaccinated and naturally infected animals. The complement fixation test (CFT) was proposed as an alternative test for international trade by the Office International des Epizooties (OIE). Additionally, alternative tests such as enzymelinked immunosorbent assay (ELISA) and indirect immunofluorescence assay (IFA) can be used for diagnosis $Q$ fever within a local context, and it can also be used during importing and exporting animals following bilateral agreements. At present, there are three ELISA commercial kits for diagnosis $Q$ fever in domestic ruminants whereas commercial kits using the IFA for veterinary investigation are not available. The diagnosis of $Q$ fever is based on the serological test and the immunofluorescence assay. The ELISA and IFA tests are more sensitive than the CFT for detection of antibody response in animals or humans with acute $Q$ fever but not for the detection of antibody response in humans with chronic $Q$ fever and in aborting cows (Sidi-Boumedine et al., 2010). The ELISA and IFA detect antibody in acutephase sera, and they are quite efficient in binding $\operatorname{IgM}$ (these antibodies predominante in the acute stage), in contrast to the $\mathrm{CF}$ test. Recent infections are difficult to demonstrate serologically by the CFT, because antibodies detected by this test can persist longer than acute stage. However, chronic and persistent infections of Coxiella burnetii are difficult to diagnose by the ELISA, because this test is more accurate in the acute stage of $Q$ fever, when the IgM predominate in the response (Jóźwik et al., 2007). Cross-reactions are the biggest source of false negative results during interpreting serological results. Cross-reactions have been described between Coxiella burnetii and Legionella pneumophila (Deyer et al., 1988; Finidori et al., 1992), Legionella micdadei (Musso \& Raoult, 1997), and Bartonella quintana and Bartonella henselae (La Scola \& Raoult, 1996).

Other techniques used for $\mathrm{Q}$ fever diagnosis include dot immunobloting, Western blotting, indirect hemolysis test and radioimmunoassay. Western blotting has been reported to be sensitive and specific. The molecular masses of antigens detected vary from 10 to $100 \mathrm{kDa}$. Antibodies reacting with 50, 80, $160 \mathrm{kDa}$ antigens are considered indicative of chronic $\mathrm{Q}$ fever (Blondeau et al, 1990). However Western blotting is very time consuming technique and the results obtained by this technique are not reproducible. Dot blotting and radioimmunobloting 
are sensitive and specific technique but radioimmunoblotting can be performed only in radioactivity equipped laboratories (Cowley et al., 1992, Doller et al., 1984).

PCR is rapid and the most sensitive technique for direct diagnosis of Coxiella burnetii and identification of shedding animal. Several PCR diagnostic assays were developed to detect Coxiella burnetii DNA including conventional PCR, nested PCR and real-time PCR (Klee et al., 2006). The PCR is adapted to a wide range of samples. The results of conventional PCR are presented in figure 2. The development of real-time PCR technology has recently allowed the quantification of Coxiella burnetii, and commercial kits are now available. The most suitable sample use in the PCR are: a vaginal swab, a placenta swab focusing the zones of necrosis or cotyledons presenting lesions, the organs (spleen, lung, liver) or the stomach contents of the aborted foetus. Besides Coxiella burnetii is also detected in the shed in faeces and milk. For direct detection of Coxiella burnetii, sampling should be targeted at pregnant animals either giving birth normally or aborting. The sampling should be carried out as soon as after abortion or parturition because the shedding level of bacteria decrease very fast. Coxiella burnetii genes such as $16 \mathrm{~S}$ rDNA, sodB, and gltA may be amplified. The threshold for quantitative PCR is not officially approved at the international level. A group of French experts has suggested that abortion in ruminants should be suggested to be caused by Coxiella burnetii when at least $10^{4}$ bacteria per gram of placenta or vaginal swabs are detected. Testing tissues or stomach contents from aborted foetuses, the same group considered that a positive result by quantitative PCR is sufficient to diagnose $\mathrm{Q}$ fever as the origin of abortion. For pooled samples, the proposed threshold is $10^{3}$ bacteria per pool (EFSA Panel on Animal Health and Welfare (AHAW), 2010). Conventional PCR is the most commonly used technique in diagnosis. This technique cannot be completely automated, due to the time between the amplification and revelation of the DNA. Moreover, conventional PCR does not distinguish animals shedding huge amounts of bacteria and those with only few bacteria. The real-time PCR is quantitative method. The fusing media that Coxiella burnetii was detected and identified by RT-PCR which, presented bacterial load greater than $10^{4}$. This concentration reflects active infection by this bacterium. Considering the frequency of secretion accompanying normal parturition and the heavy bacterial load present in the placenta or vaginal mucus of aborting females, a definitive diagnosis of infection with Coxiella burnetii as the cause of abortion can only be made if bacterial tissue concentrations are greater than $10^{4}$ bacteria per gram (Alsaleh et al., 2011).

In human, rapid nested PCR assay may be used for early diagnosis of acute $Q$ fever, using serum as the template and Light-Cycler (Roche Diagnostic, Basel, Switzerland) as the thermal cycler, named the LightCycler nested PCR assay (LCN-PCR). In this techniques the two primer pairs had different hybridisation temperatures, reaction tubes were not opened during amplification. Moreover, it is very fast techniques because both amplification and reamplification were performed within 90 minutes. However, the presence of inhibitors in the serum and usually small amount of bacterial DNA limit the efficiency of PCR for this assay. For early diagnosis of acute Q fever, where LCN-PCR is used, the serology tests should be performed together with serology in the first 2 weeks of the diseases but they should be reserved for seronegative patients in the next 2 weeks and not used later than 4 weeks following onset, when serology is highly sensitive (Fournier \& Raoult, 2003). 
The direct detection of Coxiella burnetii without using PCR or real-time PCR is very difficult because this bacteria does not grow on the standard bacteriological media, and isolation is time consuming, difficult and hazardous to perform. Moreover, the biosafety level 3 condition is required for cultivation of Coxiella burnetii in embryonated eggs, eukaryotic cell culture and laboratory animals. Although, Coxiella burnetii has been successfully isolated in guinea pig, mice and embryonated eggs, such techniques have been abandoned because they are more hazardous than in vitro cell cultures (Maurin \& Raoult, 1999). Coxiella burnetii can infect embryonated eggs and multiply within the yolk sac. The growth and multiplication of the intracellular bacterium leads to death of the embryo, usually within 14 day postinoculation (Maurin \& Raoult, 1999). The most often the Buffalo Green Monkey (GMB) cells is use for culturing this microorganism.

Although, possessing a membrane similar to gram-negative bacterium is usually stainable by the Gram techniques. The Gimenze method is usually used to stain Coxiella burnetii in laboratory cultures or clinical specimens (Gimenez, 1964).

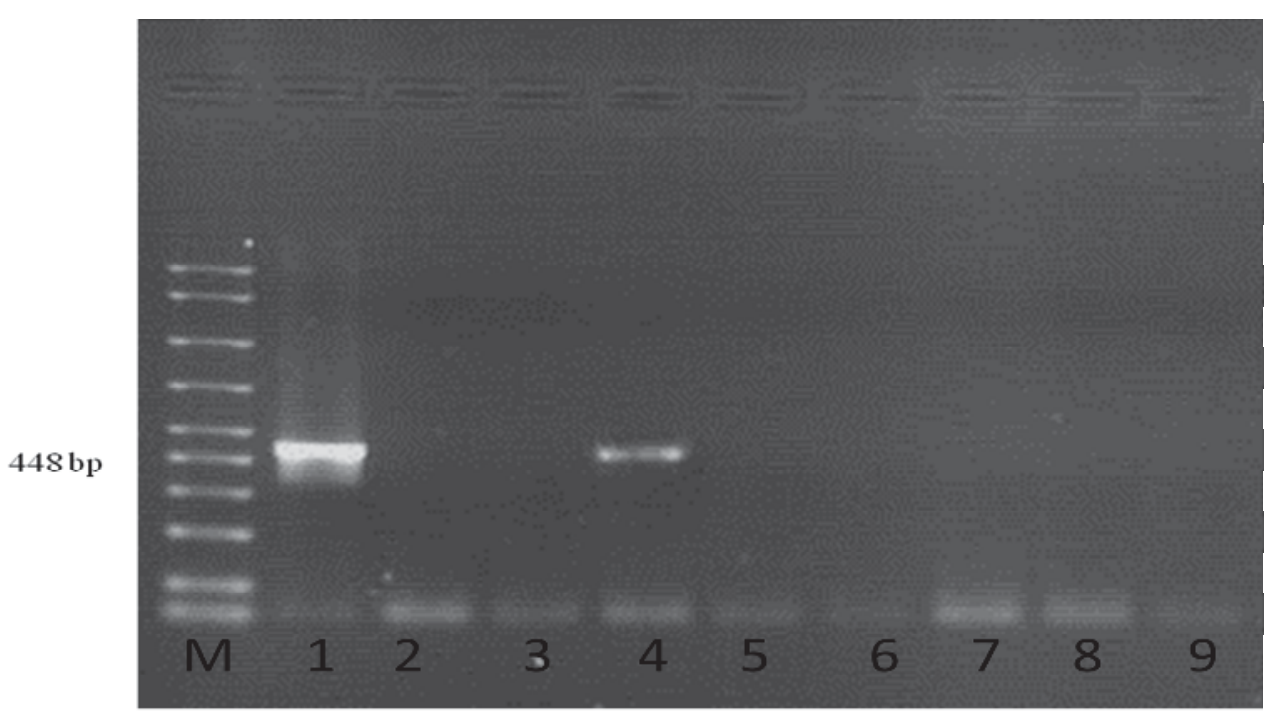

Lines:

M - marker

1 - positive control,

2 - negative control,

4 - positive sample,

3,5-9-negative sample

Fig. 2. Electrophoresis separation of amplification products. 


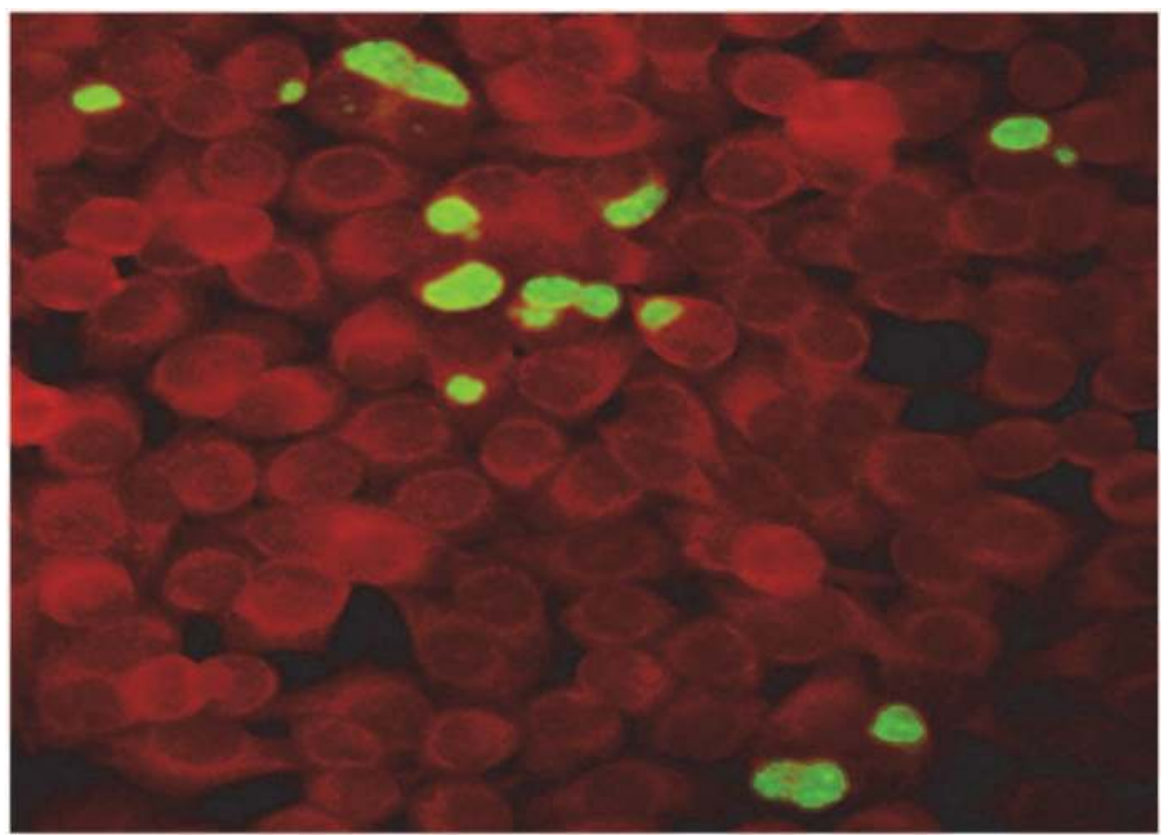

Fig. 3a. The results of immunofluorescence assay (Friedrich-Loeffler-Institute, Jena)

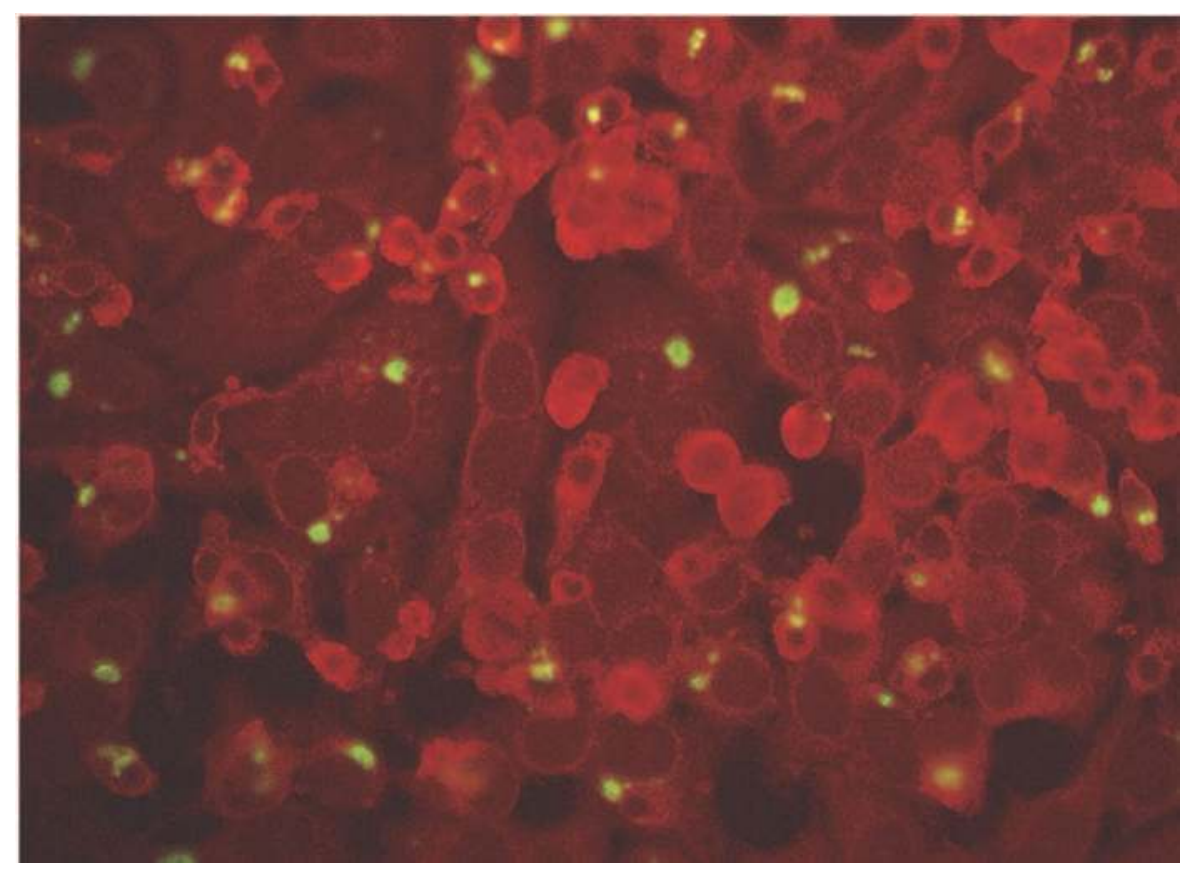

Fig. 3b. The results of immunofluorescence assay (Friedrich-Loeffler-Institute, Jena) 


\section{Prevalence of $O$ fever infection in Poland}

Human infection with Coxiella burnetii have been reported from many countries on all continents, including Poland (Lutyński, 1956). The first outbreak of $Q$ fever was diagnosed in Poland in 1956. Since then, few outbreaks of the disease both in humans and animals were recorded in the country. Several cases of human $Q$ fever occurred in Poland, however it is really not known whether this relatively low number of cases of illness is caused by the facts of its occurrence, whether or not all cases are detected and diagnosed. Data on these cases in human are presented in Table 1. Moreover, in recent times at the turn of 2008-2009, seven outbreaks of the disease were detected in cattle. These cases have occurred in the region of south-eastern Poland. In total, the disease was confirmed in more than 340 heads of cattle, the disease has been confirmed in humans handling these animals and in their family members. The other studies carried out in eastern Poland present that cattle may play an important role in epidemiology of $\mathrm{Q}$ fever, in addition to sheep and goats which are considered the main reservoirs of Coxiella burnetii (Cisak, 2003).

\begin{tabular}{|c|c|c|c|}
\hline \multirow{2}{*}{ species of animals } & \multicolumn{3}{|c|}{ Duration of Coxiella burnetii shedding } \\
\hline cow & vaginal mucus & feces & milk \\
\hline goat & not determined & 14 days & 13 months \\
\hline ewe & 14 days & 20 days & 52 days \\
\hline & 71 days & $\begin{array}{c}8 \text { days after } \\
\text { lambing }\end{array}$ & 8 days \\
\hline
\end{tabular}

Table 1. The longest observed duration of Coxiella burnetii excretion in ruminant vaginal mucus, milk and feces during the follow-up of naturally or experimentally infected herds (Arricau-Bouvery \& Rodolakis, 2005).

The European Community system for the monitoring and collecting information on zoonoses is established by Directive 2003/99/EC on the monitoring of zoonoses and zoonotic agents. According to this directive, reporting information on $\mathrm{Q}$ fever takes place on the basis of the epidemiological situation in the country, what means that the Member States should report the information whether those zoonotic agents are considered to be of importance in their country. For the reporting year 2006, 10 Member States reported information on $Q$ fever in animals. Based on the Regulation of the Minister of Agriculture and Rural Development of 24 June 2010, monitoring tests in the direction of Q fever are conducted in Poland. In order to control $Q$ fever, the blood samples from cattle or sheep and goats located in the different area of country, are tested annually. Studies conducted in the framework of this monitoring in 2010 showed the presence of seropositive units. The first study of blood serum is performed by the field laboratory. If the test result for antibodies to Coxiella burnetii is a positive sample, it is sent to the National Reference Laboratory (NRL) for re-implementation of the study. In 2010, the research review in the NRL of Q fever tested a total of 99 samples. The presence of antibodies was confirmed in 81 samples tested. Tests were conducted using the method of CFT. The samples which are confirmed as positive are also tested using real-time PCR. The positive results in this study allows the unambiguous confirmation of a case of $Q$ fever. 


\begin{tabular}{|c|r|c|}
\hline Years & The source of infection & Cases of infection in human \\
\hline $\mathbf{1 9 5 6}$ & sheep imported from Romania & 63 \\
\hline $\mathbf{1 9 5 6}$ & sheep wool & 20 \\
\hline $\mathbf{1 9 5 7 - 1 9 5 8}$ & guinea pigs - laboratory infection & 17 \\
\hline $\mathbf{1 9 6 3}$ & basils imported from America & 20 \\
\hline $\mathbf{1 9 6 3}-\mathbf{1 9 8 3}$ & no data & 1000 \\
\hline $\mathbf{1 9 8 3}$ & cattle & 35 \\
\hline $\mathbf{1 9 8 5}$ & bisons, cattle & 12 \\
\hline $\mathbf{1 9 8 5}-\mathbf{1 9 8 6}$ & cattle and small ruminants & 5 \\
\hline $\mathbf{1 9 8 5 - 1 9 8 6}$ & basils & 70 \\
\hline $\mathbf{2 0 0 5 - 2 0 0 6}$ & cattle & 21 \\
\hline $\mathbf{2 0 0 8}$ & cattle & 20 \\
\hline $\mathbf{2 0 0 9 - 2 0 1 0}$ & cattle & \\
\hline
\end{tabular}

Table 2. The infection of $Q$ fever in human in Poland

\section{References}

Alsaleh, A.A; Pellerin J.L; Rodolakis, A.; Larrat ,M.; Cochonneau, D.; Bruyas J.F. \& Fieni, F. (2011). Comparitive Immunology, Microbiol E Infectious diseases, 34, pp. 355-360

Arricau-Bouvery, N. \& Rodolakis, A. (2005). Is $Q$ fever an emerging or re-emerging zoonozis? Vet Res 36, pp. 327-349

Benson, W.W.; Brock, D.W. \& Mather, J. (1963): Serological analysis of a penitentiary group using raw milk from a $Q$ fever infected herd. Public Health Rep. 78, pp. 707-710

Blondeau, J. M; Williams, J. C. \& Marrie T. J. (1990). The immune response to phase I and II Coxiella burnetii antigensas measured by western immunobloting. Ann N Y Acad Sci, 590, pp. 187-202

Capo, Ch.; Lindberg, F.P.; Meconi, S.; Zaffran, Y.; Tardei, G.; Brown, E. J.; Raoult, D. \& Mege, J. L. (1999): Subversion of monocyte functions by Coxiella burnetii: Impairment of the cross-talk between $\alpha_{\mathrm{v}} \beta_{3}$ integrin and CR3. J Immunol, 163, pp. 6078-6085

Cisak, E.; Chmielewska-Badora, J.; Mackiewicz, B. \& Dudkiewicz, J. (2003) Prevalence of antibodies to Coxiella burnetii among farming population in eastern Poland. Ann Agric Environ Med, 10, pp. 265-267

Cowley, R.; Fernandez F., Freemantle W. \& Rutter, D. (1992). Enzyme immunoassay for Q fever: comparison with complement fixation and immunofluorescence tests and dot immunobloting. J Clin Microbiol, 30, pp. 2451-2455

Dellacasagrande, J.; Ghigo E.; Machergui-El, S.; Hammami, T. R.; Raoult, D.; Capo C. \& Mege, J. L. (2000) alpha(v) beta(3) integrin and bacterial lipolysaccharide are 
involved in Coxiella burnetii-stimulated production in tumor necrosis factor by human monocytes. Immun, 68, pp. 5673-5678

Directive 2003/99/EC of the European Parliament and of the Council of 17 November 2003 on the monitoring of zoonoses and zoonotic agents, amending Council Decision 90/424/EEC and repealing Council Directive 92/117/EEC (OJ L 325, 12.12.2003, pp. 31)

Doller, G.; Doller, P.C. \& Gerth H. J. (1984) Early diagnosis of Q fever: detection of immunoglobulin $\mathrm{M}$ by radiommunoassay and enzyme immunoassay. Eur J Clin Microbiol Infect Dis, 3, pp. 550-553

Dyer, D. E.; Gibbson, V. L.; Brady, L. M. \& Cunningham, A. L. (1988). Serological reaction to Legionella pneumophila group 4 in a patient with Q fever. J Infect Dis, 158, pp. 499-500

EFSA Panel on Animal Health and Welfare (AHAW), 2010. Scientific Option on Q fever. EFSA J., 114

Finidori, J. P.; Raoult, D., Bornstein, N.W \& Fleurette, J. (1992). Study of cross reactions between Coxiella burnetii and Legionella pneumophila using indirect immunofluorescence assay and immunoblotting. Acta Virol , 36, pp. 459-465

Fishbein, D.B. \& Raoult D. (1992) A cluster of Coxiella burnetii infections associated with exposure to vaccinated goats and their unpasteurized dairy products. Am J Trop Med Hyg, 47, pp. 35-40

Fournier, P. E. \& Raoult D. (2003). Comparison of PCR and serology assays for early diagnosis of acute Q fever. J Clin Microbiol, 41, pp. 5094-5098

Furnier, P.E.; Casalta, J.P.; Piquet P.; Tournigand, P.; Branchereau, A. \& Raoult D. (1998). Coxiella burnetii infections of aneurysms or vascular grafts: report of seven cases and revive. Clin Infect Dis, 26, pp. 116-121

Gilsdorf, A.; Kroh, C.; Grimm, S.; Jensen, E.; Wagner-Wening, C. \& Alpers, K. (2008) Large Q fever outbreak due to sheep farming near residential areas, Germany 2005. Epidemiol Infect, 136, pp. 1084-1087

Gimenez, D. F. (1964). Staining rickettsiae in yolk sac cultures. Stain Technol, 30, 135-137.

Hatchette, T.F.; Hudson, R.C.; Schlech, W.F.; Campbell, N.A.; Hatchette, J.E.; Ratnam, S.; Raoult, D.; Donovan, C. \& Marrie, T.J. (2001). Goat associated Q fever: a new disease in newfound-land. Emerg Infect Dis, 7, pp. 413-419

Hendrix, L. R; Samuel J.E. \& Mallavia L. P. (1991). Differentiation of Coxiella burnetii isolates by analysis of restriction-endonuclease-digested DNA separated by SDS-PAGE. J. Gen Microbiol, 137, pp. 269-276

Hotta, A.; Kawamura, M.; To, H.; Andoh, M.; Yamaguchi, T. Fukushi; H. \& Hirai; K. (2002). Phase variation analysis of Coxiella burnetii turning serial passage in cell culture by use of monoclonal antibodies. Infect Immun, pp. 4747-4749

Jóźwik, A.; Jakubowski, T.; Kaba, J.; Jurkowski, W.; Witkowski, L., Nowicki, M. \& Frymus, T. (2007). Evaluation of agreement of ELISA and complement fixation test in the diagnostics of $Q$ fever in cattle. Medycyna Wet, 63, pp. 655-657

Klee, S.R.; Tyczka, J.; Ellerbrok, H.; Franz, T.; Linke, S.; Baljer, G. \& Appel, B. (2006). Highly sensitive real-time PCR for specific detection and quantification of Coxiella burnetii. $B M C$, pp. 6:2

Kosatsky, T. (1984). Household outbreak of Q fever pneumonia related to a parturient cat. Lancet, pp. 1447-1449

Krumbiegel, E.R. \& Wiśniewski, H.J. (1970). Q fever in Milwaukee II consumption of infected raw milk by human volunteers. Arch Environ Health, 21, pp. 63-65 
Kruszewska, D. \& Tylewska-Wierzbowska, S. (1993). Coxiella burnetii penetration into the reproductive system of male mice, promoting sexual transmission of infection. Infect Immun, 10, pp. 4188-4195

Kruszewska, D.; Lembowicz, K. \& Tylewska-Wierzbanowska, S. (1996): Possible sexual transmission on $\mathrm{Q}$ fever among human. CID, 22, pp. 1087-1088

La Scola, B. \& Raoult, D. (1996). Serological cross reactions between Bartonella quintana, Bartonella henselae, and Coxiella burnetii. J Clin Microbiol, 34, pp. 2270-2274

Lepe, J.A. \& Guerro, F.J.; Del Castillo, E. (1999): The epidemiology of Q fever in the northern area of Huelva, Spain. Enferm Infecc Microbiol Clin, 17, pp. 65-68

Little, T.W.A. (1999). Q fever. Br Vet J, 139, pp. 277-283

Lutyński, R. (1956). First focus of Q fever on the territory of Poland. Przegl Lek 12, pp. 187188

Marmion, B. P.; Ormsebee R. A.; Kyrkou, M. \& Wright, D.; Worswick, A.; Cameron, S.; Esterman, A.; Feery B.; Collins W. (1984). Vaccine prophylaxis of abattoirassociated Q fever. Lancett, pp. 611-6161

Maurin, M. \& Raoult, D. (1999). Q fever. CMR, pp. 518-553

Moquin, R.R. \& Moquin, M.E (2002). Weapons of mass destruction: biological. Neurosurg Focus, 12, pp. 1232-1236

Muskens, J.; Engelen, E.; Maanen van, C.; Bartels, C. \& Lam, T. J. G., M. (2011). Prevalence of Coxiella burnetii infection in Dutch dairy herds on the testing bulk tank milk and individual samples by PCR and ELISA. Vet Rec, 168, pp. 79

Musso, D.\& Raoult. (1997). Serological cross-reactions between Coxiella burnetii and Legionella micdadei. Clin Diagn Lab Immunol, 4, pp. 208-212

Niemczuk, K. (2010) Q Fever - epidemiology, zoonotic aspects and administrative proceedings. PIWet-PIB, Pulawy, pp. 1-35

Prusakowski, M. (2001). Bioterror. Jak się nie dać zabić. Tower Press, Gdańsk, pp. 66-68.

Roest, I.J.H.; Ruuls, R.C.; Tilburg, J.J.H.C; Nabuurs-Franssen, M.H. \& Klaassen C.H.W. at all. Emerg Infect Dis, 4, 668-675

Seshardi, R.; Paulsen, I.T.; Elisen, J.A.; Read, T.D.; Nelson, K.E.; Nelson, W.C.; Ward, N.L.; Tettelin, H.; Davidsen, T.M.; Beanan, M.J.; Deboy, R.Y.; Daugherty, S.C.; Brinkac, L.M.; Madupu, R.; Dodson, R.J.; Khouri, H.M.; Lee, K.H.; Carty, H.A.; Scanlan, D.; Heinzen, R.A.; Thompson, H.A.; Samuele, J.E.; Fraser, C.M. \& Heidelberg, J.F. (2003). Complete genome sequence of the Q-fever pathogen Coxiella burnetii. Proc Natl Acad Sci USA, pp. 5455-5460

Sidi-Boumedine, K.; Rousset, E.; Henning K.; Ziller, M.; Niemczuk, K.; Roest H.I.J. \& Thiéry R. (2010). Development of harmonised schemes for the monitoring and reporting of $\mathrm{Q}$ fever in animals in the European Union. Scientific. Scientific report submitted to EFSA, www.efsa.europa.eu/de/supporting/pub/48e.htm

Spicer A.J. (1998) Military significance of Q fever: a review. J Roy Soc Med, 71, pp. 762-765

Vodkin, M. H.; Williams, J. C. \& Stephenson E. H. (1986). Genetic heterogeneity among isolates of Coxiella burnetii. J Gen Microbiol, 132, pp. 455

Webster, J. P.; Lloyd, G. \& Macdonald D. W. (1995). Q fever (Coxiella burnetii) reservoir in wild brown rat (Rattus norvegicus) populations in the UK. Parasitology, 110, pp. 3135

Willems, J. C.; Jäger C. \& Baljer, G.: (1998). Physical and genetic map of the obligate intracellular bacterium Coxiella burnetii. J Bacteriol, 180, pp. 3816-3822 


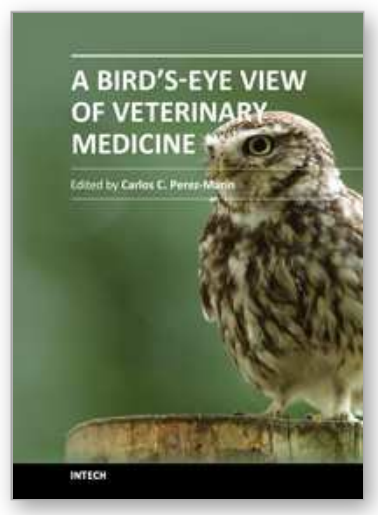

\author{
A Bird's-Eye View of Veterinary Medicine \\ Edited by Dr. Carlos C. Perez-Marin
}

ISBN 978-953-51-0031-7

Hard cover, 626 pages

Publisher InTech

Published online 22, February, 2012

Published in print edition February, 2012

Veterinary medicine is advancing at a very rapid pace, particularly given the breadth of the discipline. This book examines new developments covering a wide range of issues from health and welfare in livestock, pets, and wild animals to public health supervision and biomedical research. As well as containing reviews offering fresh insight into specific issues, this book includes a selection of scientific articles which help to chart the advance of this science. The book is divided into several sections. The opening chapters cover the veterinary profession and veterinary science in general, while later chapters look at specific aspects of applied veterinary medicine in pets and in livestock. Finally, research papers are grouped by specialisms with a view to exploring progress in areas such as organ transplantation, therapeutic use of natural substances, and the use of new diagnostic techniques for disease control. This book was produced during World Veterinary Year 2011, which marked the 250th anniversary of the veterinary profession. It provides a fittingly concise and enjoyable overview of the whole science of veterinary medicine.

\title{
How to reference
}

In order to correctly reference this scholarly work, feel free to copy and paste the following:

Krzysztof Niemczuk and Monika Szymańska-Czerwińska (2012). Epidemiology, Zoonotic Aspect and Current Epidemiological Situation of Q Fever in Poland, A Bird's-Eye View of Veterinary Medicine, Dr. Carlos C. PerezMarin (Ed.), ISBN: 978-953-51-0031-7, InTech, Available from: http://www.intechopen.com/books/a-bird-s-eyeview-of-veterinary-medicine/epidemiology-zoonotic-aspects-and-current-epidemiological-situation-of-q-feverin-poland

\section{INTECH}

open science | open minds

\section{InTech Europe}

University Campus STeP Ri

Slavka Krautzeka 83/A

51000 Rijeka, Croatia

Phone: +385 (51) 770447

Fax: +385 (51) 686166

www.intechopen.com

\section{InTech China}

Unit 405, Office Block, Hotel Equatorial Shanghai

No.65, Yan An Road (West), Shanghai, 200040, China 中国上海市延安西路65号上海国际贵都大饭店办公楼 405 单元

Phone: +86-21-62489820

Fax: +86-21-62489821 
(C) 2012 The Author(s). Licensee IntechOpen. This is an open access article distributed under the terms of the Creative Commons Attribution 3.0 License, which permits unrestricted use, distribution, and reproduction in any medium, provided the original work is properly cited. 